\title{
RESEARCH
}

Open Access

\section{Intraindividual validation of 4D flow measurement against 2D flow measurements in complex flow patterns in routine clinical cardiovascular magnetic resonance of bicuspid aortic valve}

\author{
Ahmed Kharabish ${ }^{1,2^{*}}$ D, Kristina Belker ${ }^{3}$, Stefan Martinoff ${ }^{4}$, Peter Ewert ${ }^{3}$, Anja Hennemuth ${ }^{5}$, Markus Huellebrand ${ }^{5}$, \\ Heiko Stern ${ }^{3}$ and Christian Meierhofer ${ }^{3}$
}

\begin{abstract}
Background: Comparing four-dimensional flow against two-dimensional flow measurements in patients with complex flow pattern is still lacking. This study aimed to compare four-dimensional against the two-dimensional flow measurement in patients with bicuspid aortic valve and to test potentials of four-dimensional operatordependent sources of error.

Results: The two- and four-dimensional flow data sets of sixteen patients with bicuspid aortic valve and eighteen healthy subjects were studied. Flow analyses were performed by two observers blindly. Patients with bicuspid aortic valve mean differences between the two- and four-dimensional measurements in both observers were -8 and $4 \mathrm{ml}$, respectively. Four-dimensional measurements resulted in systematically higher flow values than the twodimensional flow in bicuspid aortic valve patients. The upper and lower limits of agreement between the two- and four-dimensional measurements by both observers were $+12 /-28 \mathrm{ml}$ and $+14 /-21 \mathrm{ml}$, respectively. In the healthy volunteers, mean differences between the two- and four-dimensional measurements in both observers were \pm 0 and + $1 \mathrm{ml}$, respectively. The upper and lower limits of agreement between the two- and four-dimensional measurements by both observers were $+21 /-18 \mathrm{ml}$ and $+12 /-13 \mathrm{ml}$, respectively. Inter-observer variability in four-dimensional flow measurement was $4 \%$ mean net forward flow in bicuspid aortic valve patients and $8 \%$ in healthy volunteers.

Conclusion: Inter-observer variability in four-dimensional flow assessment is $8 \%$ or less which is acceptable for clinical cardiac MRI routine. There is close agreement of two- and four-dimensional flow tools in normal and complex flow pattern. In complex flow pattern, however, four-dimensional flow measurement picks up 4-9\% higher flow values. It seems, therefore, that four-dimensional flow is closer to real flow values than two-dimensional flow, which is however to be proven by further studies.
\end{abstract}

Keywords: CMRI, CHD, BAV, 4D flow

\footnotetext{
* Correspondence: Ahmed.kharabish@lhch.NHS.UK

'Department of Radiology, Cairo University Hospitals, Cairo, Egypt

${ }^{2}$ Department of Radiology, Liverpool Heart and Chest Hospital, Liverpool, UK

Full list of author information is available at the end of the article
}

\section{Springer Open}

(c) The Author(s). 2020 Open Access This article is licensed under a Creative Commons Attribution 4.0 International License, which permits use, sharing, adaptation, distribution and reproduction in any medium or format, as long as you give appropriate credit to the original author(s) and the source, provide a link to the Creative Commons licence, and indicate if changes were made. The images or other third party material in this article are included in the article's Creative Commons licence, unless indicated otherwise in a credit line to the material. If material is not included in the article's Creative Commons licence and your intended use is not permitted by statutory regulation or exceeds the permitted use, you will need to obtain permission directly from the copyright holder. To view a copy of this licence, visit http://creativecommons.org/licenses/by/4.0/. 


\section{Background}

Two-dimensional velocity-encoded cine magnetic resonance imaging flow analysis is an established technique for assessing hemodynamics in cardiovascular magnetic resonance (MRI) [1-3] in congenital heart diseases (CHD) [2].

Intraindividual validation of the quantification of fourdimensional flow tool against two-dimensional flow tool was previously performed mostly in normal subjects [4]. Visualization of abnormal flow patterns by fourdimensional flow tool following surgery for complex CHD [5-8] was previously published as well.

However, the estimation of the four-dimensional operator-dependent source of error during segmentation and post processing is scarcely discussed. Moreover, comparing four-dimensional flow against two-dimensional flow measurements in patients with complex flow pattern is still lacking.

Therefore, the purpose of this study was as follows:

1. To test the four-dimensional operator-dependent sources of error.

2. To test the agreement of four-dimensional against two-dimensional flow measurements in the ascending aorta of patients with bicuspid aortic valve, who present with abnormal helical flow pattern and normal subjects.

\section{Methods}

Retrospectively (2012-2013) the quantitative flow in the ascending aorta was analyzed in 16 patients (6 females) with bicuspid aortic valve (BAV) disease and in 18 (7 females) healthy volunteers (HV).

Patients > 7 years, no past congenital heart defect other than BAV, no arterial hypertension, no thorax deformations, a diameter of the ascending aorta $<4.5 \mathrm{~cm}$ in adults and $<2.2 \mathrm{~cm} / \mathrm{m}^{2}$ in children, no significant aortic valve regurgitation, and a flow velocity through the aortic valve of $<250 \mathrm{~cm} / \mathrm{s}$ by echocardiography no absolute contraindications to CMR imaging were included. Healthy volunteers were matched to the BAV group by sex and age ( \pm 2 years) to serve as a control group. Individuals who did not meet the aforementioned criteria were excluded.

All subjects were studied on a standard cardiac 1.5 Tesla MRI-scanner, and a standard cardiac 12channel coil was used for all patients (MAGNETOM Avanto, Siemens Healthcare, Erlangen, Germany). A written informed consent was obtained from all patients. At the beginning of the study, localizers were obtained in three orthogonal slices for registration of the thoracic anatomy in order to plan the following sequences.
Through plane two-dimensional phase contrast velocity encoding flow measurement

Standard through plane two-dimensional phase contrast velocity encoding imaging of the ascending aorta was performed, as previously described $[9,10]$. Parameters in the $2 \mathrm{D}$ phase contrast velocity encoding imaging were free breathing (typical acquisition times: around $3 \mathrm{~min}$ ), retrospective ECG gating, and the velocity encoding set to $200 \mathrm{~cm} / \mathrm{s}$.

Slice thickness was $5 \mathrm{~mm}$, repetition time $36.7 \mathrm{~ms}$, echo time $3.09 \mathrm{~ms}$, flip angle $30^{\circ}$, averages 3, segmentation 3, rectangular field of view 260 to $330 \times 330 \mathrm{~mm}$, matrix 256 $\times 256$. Data were reconstructed to provide 30 magnitude and phase (velocity-mapped) images per cardiac cycle.

The imaged vessel's region of interest was always positioned at iso-center of the magnet to maximize gradient fidelity. Furthermore, the ECG was continuously observed during acquisition. The running acquisition was always aborted when more than three extra systoles were noted $[9,10]$.

Flow measurement of the ascending aorta was performed at the level of the pulmonary artery bifurcation. Post processing was done by manual contour delineation using the Argus software tool (Siemens ${ }^{\circ}$ ) by cardiac MRI experts. In all results depicted, aortic flow was defined as net forward aortic flow.

\section{Four-dimensional flow measurement}

Quantitative flow measurement of the ascending aorta by the four-dimensional flow sequence was performed using a time-resolved three-dimensional phase-contrast sequence with three-directional velocity encoding as previously described [11]. No contrast agent was used, and respiratory gating was achieved by a respiratory navigator. All data were measured in a sagittal-oblique volume that included the entire thoracic aorta. Velocity encoding $\mathrm{Vx}, \mathrm{Vy}$, and $\mathrm{Vz}$ set to $200 \mathrm{~cm} / \mathrm{s}$ similar to the 2D phase contrast velocity encoding.

Assessment of flow was performed using the FraunhoferMEVIS flow software (Fraunhofer MEVIS-Institute for Medical Image Computing). Once ROI was fully defined for each time step throughout the cardiac cycle, the acquired data were fully processed for final quantification (Figs. 1 and 2). In all results depicted, aortic flow was defined as net forward aortic flow. Flow measurement of the ascending aorta was performed at the level of the pulmonary artery bifurcation (Fig. 1).

\section{Interobserver variability}

A second investigator, blinded to the first assessment, using the same software tools, performed a second assessment of the flow. Contour drawing in the ascending aorta was performed by two experienced members of the cardiac MRI team (A.K. and K.B.) who were familiar 


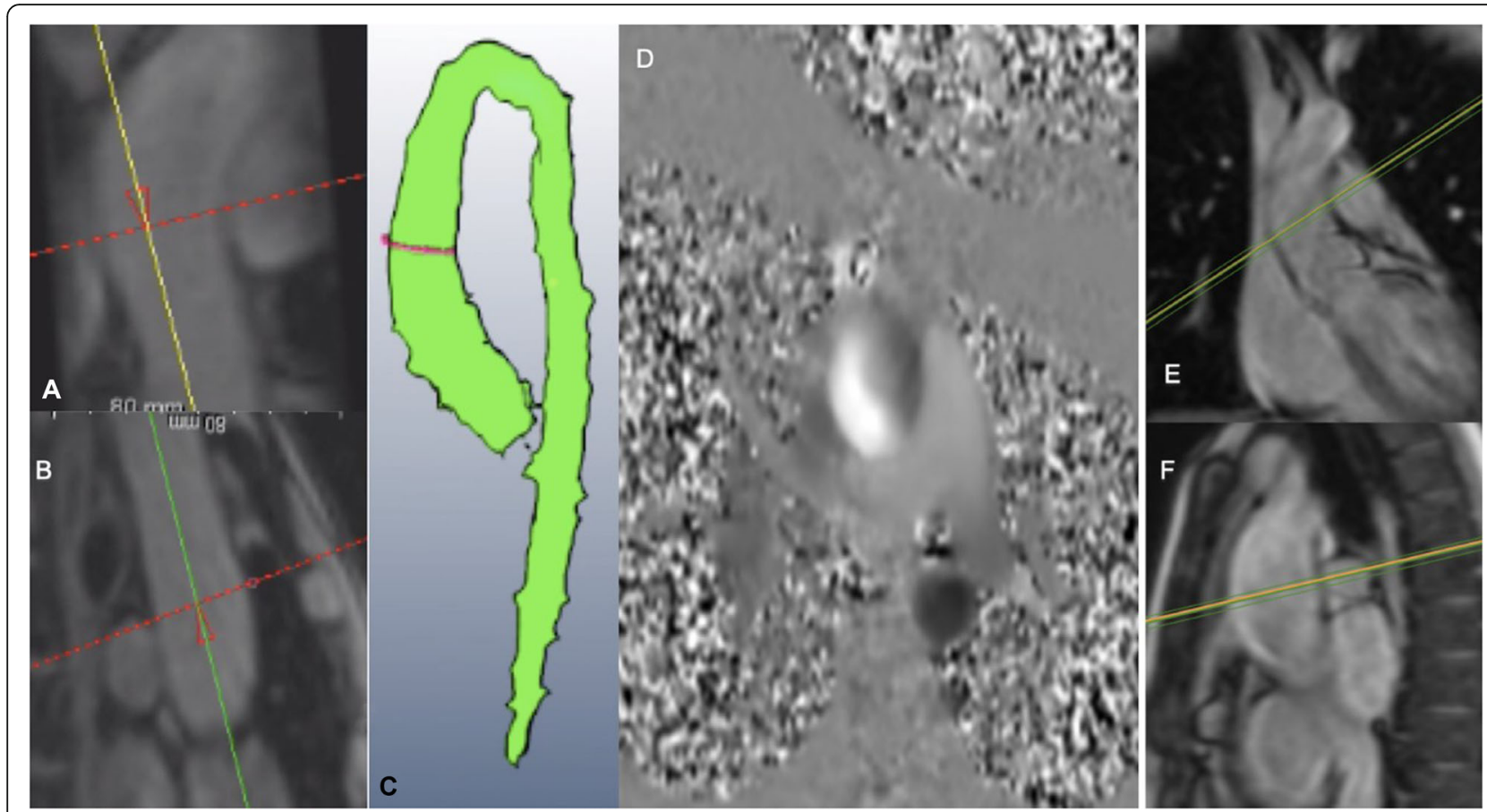

Fig. 1 Assessment of aortic 4D-flow, iso-surface images of the aorta (green) are produced. The post processing manual contour delineation was performed at the level of the pulmonary artery bifurcation (cross lines)

with the Mevis software flow tool. In the fourdimensional flow measurement of the ascending aorta, iso-surface images of the aorta are produced. The postprocessing manual contour delineation was performed at the level of the pulmonary artery bifurcation (Fig. 1).

\section{Statistical analysis}

Linear regression plots (Fig. 3) were used to describe the correlation (Pearson correlation and coefficient of determination) of net flow within the different techniques (two-dimensional versus four-dimensional phase contrast velocity encoding).

Bland-Altman plots (Fig. 4) were used to describe the agreement of ascending aorta net flow within the different techniques (two- versus four-dimensional phase contrast velocity encoding) as well as the interobserver variability of the four-dimensional net flow.

The individual percentage difference was defined as the individual difference between two measurements divided by their mean and multiplied by 100 .

Differences between two- and four-dimensional flow analyses by each observer and interobserver differences were tested by Student's $t$ test for paired variables. Statistical significance was set at $p<0.05$.

\section{Results}

\section{Bicuspid aortic valve group data}

A tendency of higher four-dimensional flow values compared to two-dimensional flow values was found by both observers (Fig. 3), which reached statistical significance in observer one $(p=0.007)$.

The 16 patients with BAV had a median age of 26 years (range 18-44 years) and a regurgitation fraction through the aortic valve median (min-max) of $2 \%$ (range $0-7 \%$ ) using two-dimensional flow analysis and of $1 \%$ (range 0-6\%) using four-dimensional flow analysis with observer one. In observer two, median regurgitation was 0\% (range 0-8\%) using four-dimensional flow.

Observer one (Figs. 3 and 4) Significant difference was found between two- and four-dimensional measurements $(p=0.007)$. The upper and lower limits of agreement in the bicuspid aortic valve group were $12 \mathrm{ml}$ and - $28 \mathrm{ml}$, respectively with a mean difference of $-8 \mathrm{ml}$ corresponding to $8 \%$ mean net flow.

Observer two (Figs. 3 and 4) No significant difference was found between two- and four-dimensional measurements $(p=0.102)$. The upper and lower limits of agreement in the bicuspid aortic valve group were $14 \mathrm{ml}$ and - $21 \mathrm{ml}$, respectively with a mean difference of $-4 \mathrm{ml}$ corresponding to mean percentage difference of $4 \%$.

\section{Healthy volunteers' data}

One of the healthy subjects was accidently found to have a helical flow pattern despite having a tricuspid aortic valve and no clinical symptoms. He was excluded from further analysis. The remaining 17 subjects had a 


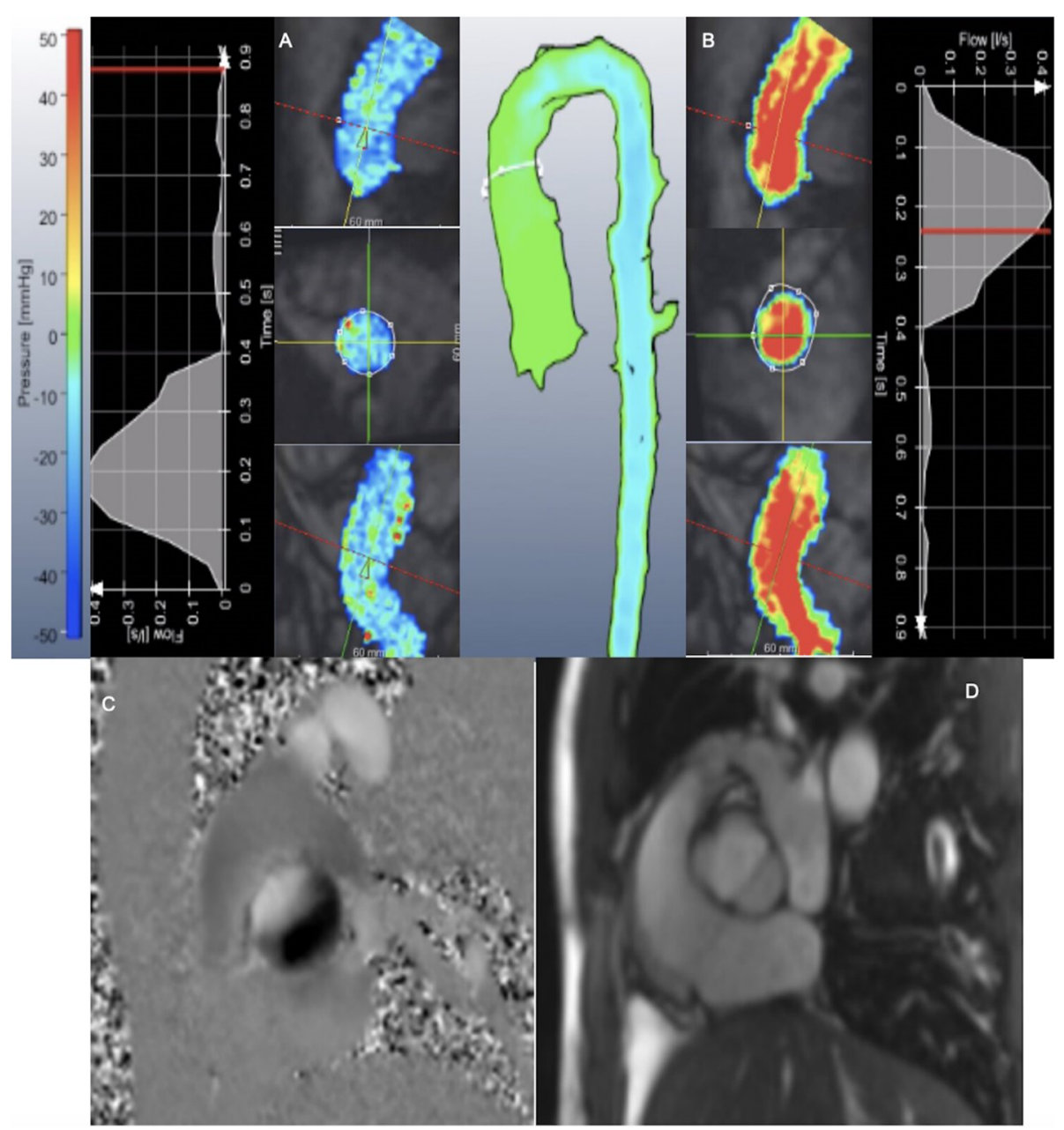

Fig. 2 Assessment of flow was performed using the 4D-flow software. Once ROI was fully defined for each time step throughout the cardiac cycle, the acquired data were fully processed for final quantification

median age of 25 years (range $8-42$ years) and a regurgitation fraction through the aortic valve median (min$\max )$ of $0 \%(0-3 \%)$ using two-dimensional flow analysis and of $0 \%(0-2 \%)$ using four-dimensional flow analysis as recorded by both observers.

Observer one (Figs. 3 and 4) No significant difference between two- and four-dimensional measurements was found $(p=0.55)$. The upper and lower limits of agreement between two- and four-dimensional measurements in the healthy volunteers group were $21 \mathrm{ml}$ and $-18 \mathrm{ml}$ respectively with a mean difference of $1 \mathrm{ml}$ corresponding to mean percentage difference of $9 \%$.

Observer two (Figs. 3 and 4) No significant difference between two- and four-dimensional measurements was found $(p=0.93)$. The upper and lower limits of agreement in the health volunteer's group were $12 \mathrm{ml}$ and -
$13 \mathrm{ml}$ respectively with a mean difference of $0 \mathrm{ml}$, corresponding to mean percentage difference of $5 \%$.

Interobserver variability and effect of post processing the four-dimensional net flow (Fig. 4)

No significant difference was found in the fourdimensional measurements between both observers in the healthy volunteers' group $(p=0.49)$ as well as in the bicuspid aortic valve group $(p=0.541)$

Observer one tended to have bigger four-dimensional values; the upper and lower limits of agreement in healthy volunteers' group were $14 \mathrm{ml}$ and $-17 \mathrm{ml}$, respectively, with a mean difference of $-1 \mathrm{ml}$ corresponding $8 \%$. The upper and lower limits of agreement in bicuspid aortic valve group were $19 \mathrm{ml}$ and $-11 \mathrm{ml}$, respectively, with a mean difference of $-4 \mathrm{ml}$ corresponding to $4 \%$ mean net flow. 


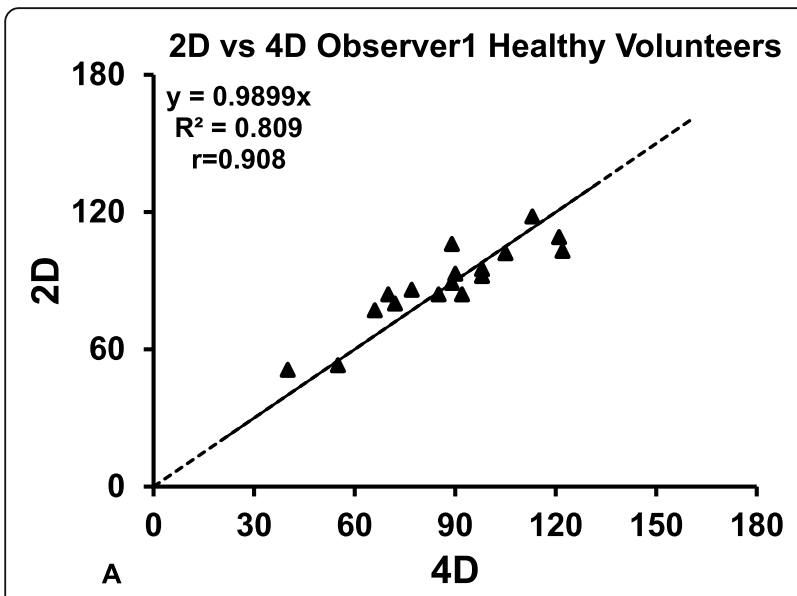

2D vs 4D Observer2 Healthy Volunteers

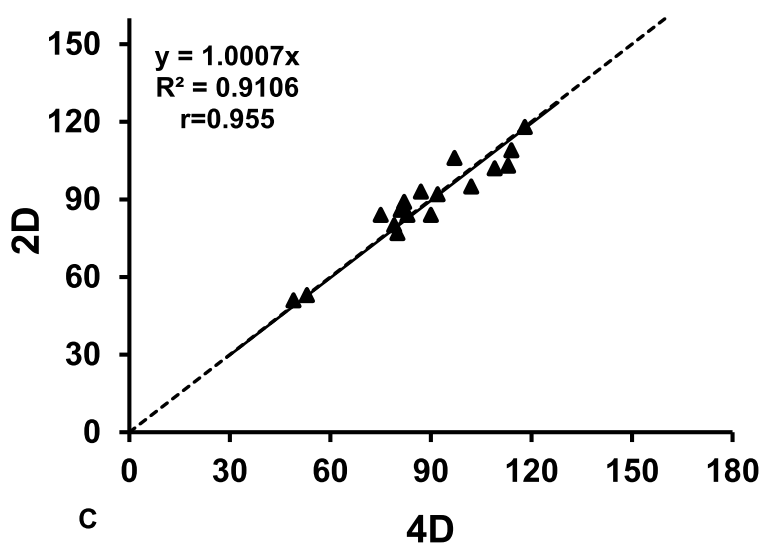

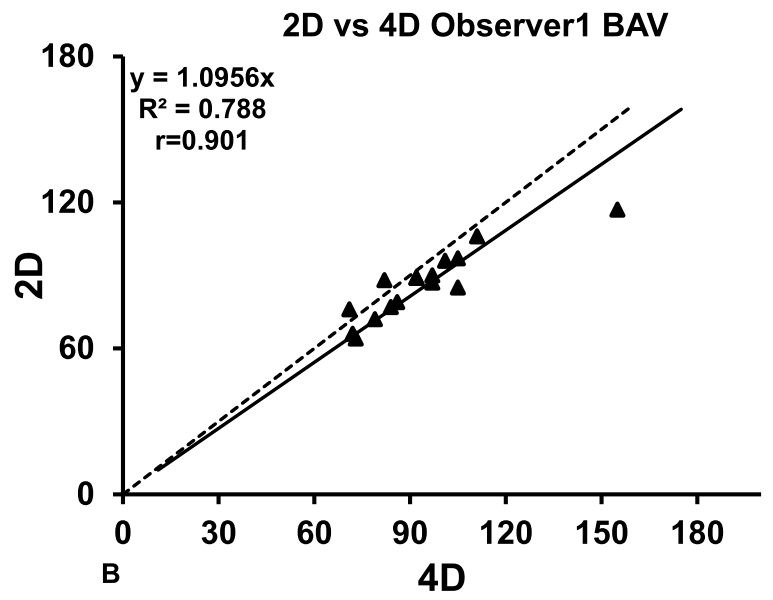

2D vs 4D Observer2 BAV

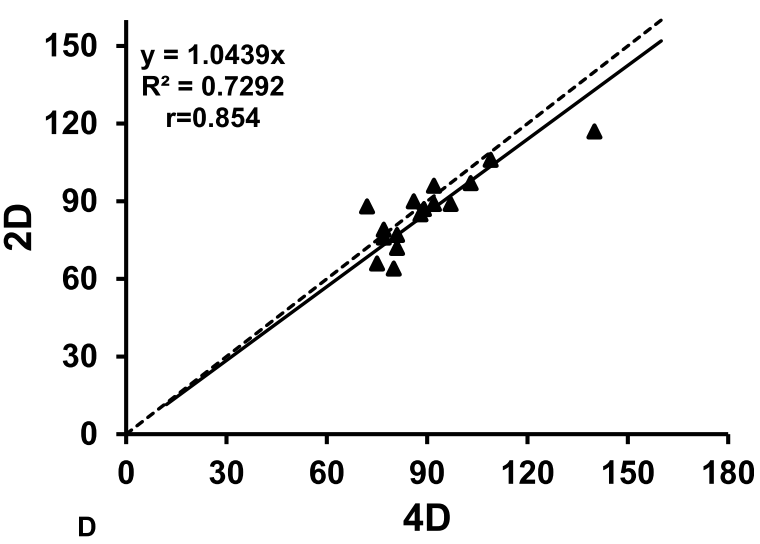

Fig. 3 Linear regression correlation: net flow values $(\mathrm{ml})$ in the ascending aorta of both techniques by the two observers are plotted on both $X$ axis and $Y$-axis. The $X$-axis represents the four-dimensional (4D) method of flow analysis while the $Y$-axis represents the two-dimensional (2D) method of flow analysis in all four graphs. Graphs $\mathbf{a}$ and $\mathbf{c}$ represent healthy volunteers, $\mathbf{b}$ and $\mathbf{d}$ represent patients with bicuspid aortic valve (BAV). A line of identity (dashed) $y=x$ is added. The regression line (solid) indicates the offset between the two methods

\section{Discussion}

The study showed close agreement between the flow assessment using standard two-dimensional phase contrast velocity encoding through plane flow analysis and fourdimensional flow measurements both in healthy volunteers and in bicuspid aortic valve patients with helical blood flow. In Bland Altman analysis, mean differences between both methods were maximally $9 \%$ of the mean net aortic flow. However, there was a tendency for fourdimensional measurements to have slightly higher flow values in complex flow pattern. This tendency reached even statistical significance for bicuspid aortic valve patients by one of the observers.

A similar finding was described by Nordmeyer and colleagues [12], who described higher peak velocities in four-dimensional values in the aortic segment when compared to the corresponding two-dimensional segment, assessed in patients with semilunar valve stenosis. Theoretically, four-dimensional flow tool should be closer to reality than two-dimensional flow measurements because it measures blood flow in all three vectors $[13,14]$, which should be especially important in the presence of helical flow pattern.

Important factors, which are able to cause differences between two- and four-dimensional flow measurements, and beyond those, the previously mentioned study by Nordmeyer and colleagues [12], are the different isocentering. We think that iso-centering plays a major role in the assessment of the four-dimensional flow measurements [13]. This effect, however, is not dominant in this study, as both in two- and four-dimensional flow measurements the iso-center was placed in the ascending aorta. It may, however, become more important, when flow measurements from the four-dimensional data set are performed in segments remote from the iso-center.

Many sources of errors of the four-dimensional flow may occur in patients with complex flow pattern [15]. Most of the previous studies had discussed those errors related to 

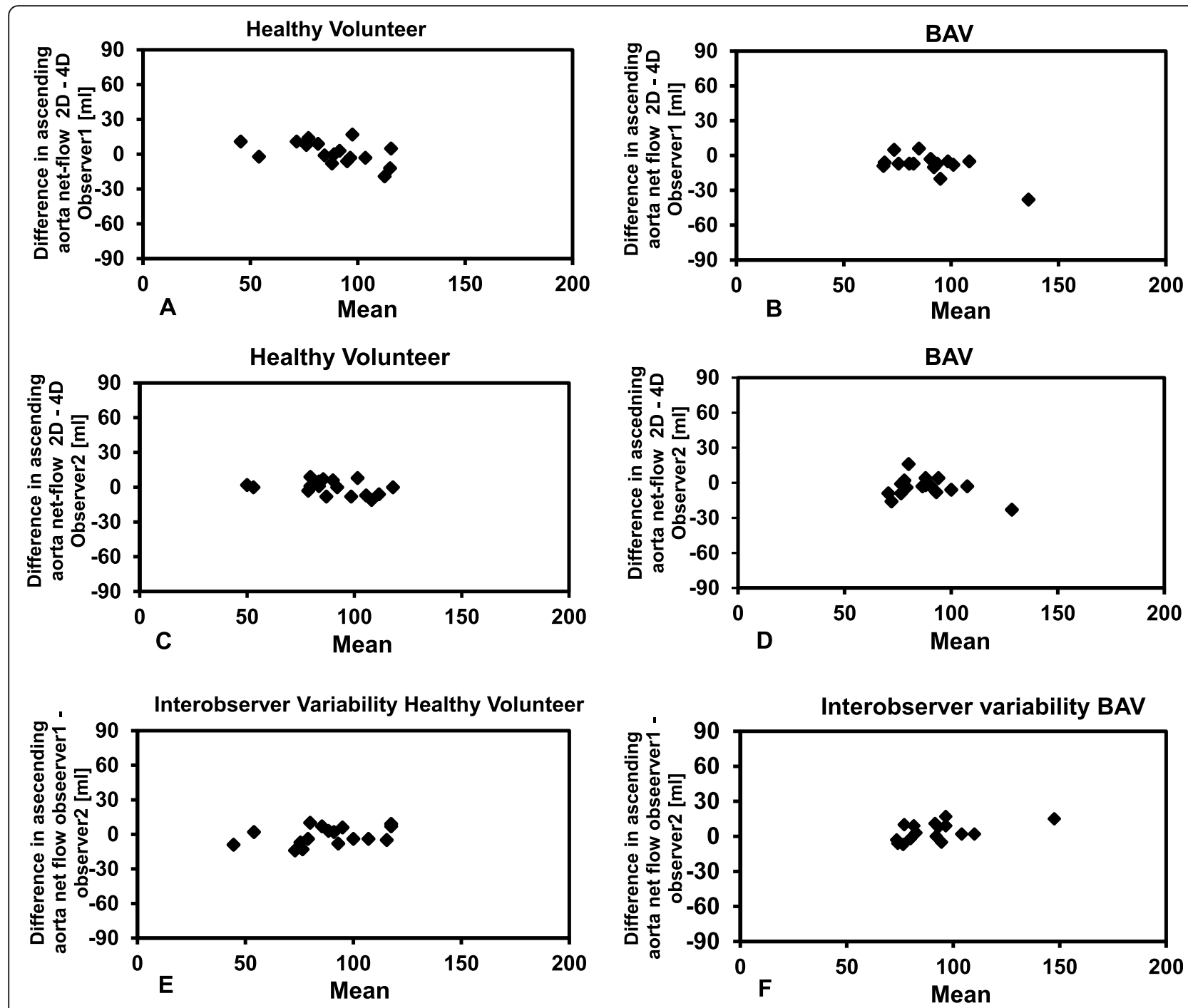

Fig. 4 Bland Altman plots: the $Y$-axis represents the individual differences of the ascending aorta net flow (ml) measurements by the two methods; two-dimensional (2D) and four-dimensional (4D) flow analysis by the two observers (upper two rows). In the lower row $Y$-axis represents the individual differences of the interobserver variability of the ascending aorta net flow measurements by the $4 D$ method. $X$-axis represents the mean. Graphs $\mathbf{a}, \mathbf{c}$, and $\mathbf{e}$ represent healthy volunteers, and graphs $\mathbf{b}, \mathbf{d}$, and $\mathbf{f}$ represent patients with bicuspid aortic valve (BAV)

the data acquisition during the scanning itself [15]. One of the advantages of four-dimensional flow cardiac MRI is the potentiality of analyzing different planes at any location (Fig. 5) within the acquisition volume retrospectively [14]. However, the variations in segmentation and contouring are additional sources of variance because they are operator dependent during the post processing in the fourdimensional measurements. In clinical practice this may cause variability in the results even in the same institute. The interobserver variability during the post processing of four-dimensional flow in the current study was small and can be neglected in clinical routine. It reached maximally $8 \%$ in healthy volunteers and $4 \%$ in complex flow by bicuspid aortic valve.
It is therefore paramount within the same institute to standardize the level of contouring and segmentation of the aorta during the post processing of the fourdimensional flow. In the current study, the measurements of the aortic flow were located at the level of the main pulmonary artery.

Previous validation studies in healthy volunteers and in patients with complex vascular pattern showed close correlation between four-dimensional and two-dimensional flow measurements $[12,16]$. For instance, the study of Nordmeyer and colleagues [12], however, used a different acquisition and the flow tool software yet did not study interobserver variability in four dimensional measurements. 


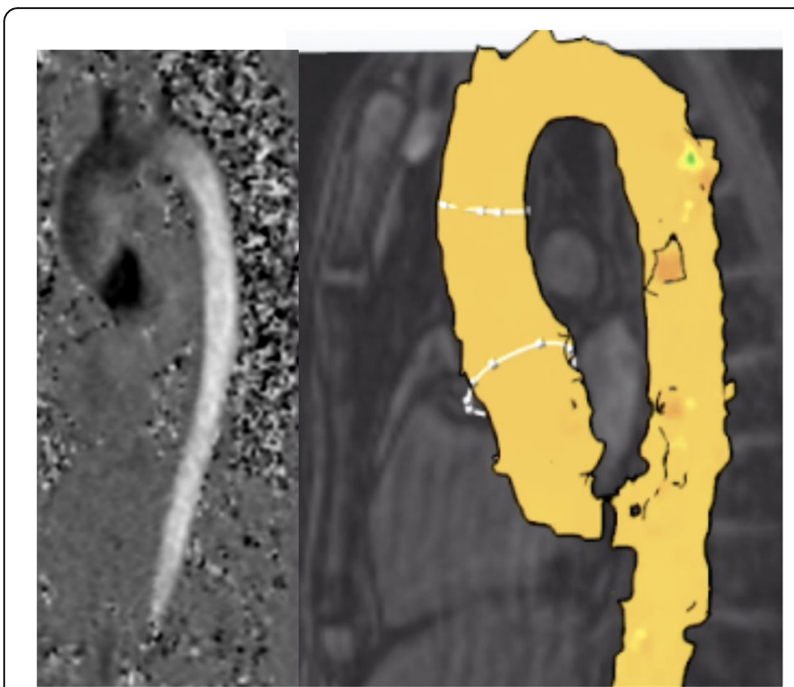

Fig. 5 Four-dimensional flow cardiac MRI analyzing different planes within the acquisition volume retrospectively

A very recent study by Ebel et al. [17] compared the 4D flow in the BAV and HV. They studied the stability of the 4D flow across different strength magnetic fields (1.5 Tesla versus 3 Tesla). They found a stable performance of $4 \mathrm{D}$ flow MRI at $1.5 \mathrm{~T}$ and $3 \mathrm{~T}$ regarding flow assessment. Our study compared 2D versus $4 \mathrm{D}$ flows as well as tested the source of error in the 4D flow assessment.

Our data support, that four-dimensional flow measurement, which offers a wide spectrum of new applications in congenital heart disease, produces reliable flow measurements. Therefore, it was paramount to discuss other potential sources of error which may occur during post processing and/or data quantification after the scan. This study showed that the operator-dependent error during four-dimensional post-processing is not significant when describing its limitations or when comparing four-dimensional flow to the recently developing computed flow dynamics.

Our study agree with the conclusion of Lewandowski et al. [18]; efforts are required to standardize not only the four-dimensional flow as regard the scanning parameters but also the post processing's tools and reporting the data after the scan to increase the capacity to successfully convert from theoretical use to clinical practice.

\section{Limitations}

The limitation of the study is the small number of included individuals. However, we have put a strict inclusion criterion in order to collect a homogeneous population with only BAV. The inclusion criteria were chosen by cutoff values for BAV and the diameter of the ascending aorta according to the published guidelines [19].

\section{Conclusion}

Inter-observer variability in four-dimensional flow assessment is $8 \%$ or less which is acceptable for clinical cardiac MRI routine. There is close agreement of twoand four-dimensional flow tools in normal and complex flow pattern. In complex flow pattern, however, fourdimensional flow measurement picks up 4-9\% higher flow values. It seems, therefore, that four-dimensional flow is closer to real flow values than two-dimensional flow, which is however to be proven by further studies.

\section{Abbreviations \\ 2D: Two-dimensional; 4D: Four-dimensional; BAV: Bicuspid aortic valve; CHD: Congenital heart disease; HV: Healthy volunteers; ROI: Region of interest; ECG: Electrocardiogram; MRI: Magnetic resonance imaging}

\section{Acknowledgements}

We are very grateful to Sohrab Fratz, MD, PhD, who left us too early, for this scientific enthusiasm and knowledge. Sohrab Fratz was deeply involved in the scientific discussion and design of this manuscript.

\section{Authors' contributions}

$\mathrm{AK}, \mathrm{KB}, \mathrm{CM}$, and $\mathrm{HS}$ analyzed and interpreted the patient MRI. AK, $\mathrm{KB}, \mathrm{AH}$, and $\mathrm{MH}$ analyzed and interpreted the $4 \mathrm{D}$ flow patient data. SM, HS, PE, and $\mathrm{CM}$ reviewed patients' data and the manuscript. AK and HS designed the manuscript. All authors have read and approved the manuscript.

\section{Funding}

Not applicable (no funding was provided). This research received no specific grant from any funding agency, commercial or not-for-profit sectors.

Availability of data and materials

The datasets analyzed during the current study are available from the corresponding author on reasonable request.

Ethics approval and consent to participate

- Institutional ethical clearance was waived; this study is a retrospective study. - Written consent was obtained from patients or their authorized representatives. - All procedures contributing to this work comply with the ethical standards of the Helsinki Declaration of 1975, as revised in 2008.

\section{Consent for publication}

All patients included in this research gave written informed consent to publish the data contained within this study. If the patient was less than 16 years old, deceased, or unconscious when consent for publication was requested, written informed consent for the publication of this data was given by their parent or legal guardian.

\section{Competing interests}

The authors declare that they have no competing interests.

\section{Author details}

${ }^{1}$ Department of Radiology, Cairo University Hospitals, Cairo, Egypt.

${ }^{2}$ Department of Radiology, Liverpool Heart and Chest Hospital, Liverpool, UK ${ }^{3}$ Department of Paediatric Cardiology and Congenital Heart Defects, Deutsches Herzzentrum München, Technische Universität München, Munich, Germany. ${ }^{4}$ Department of Radiology, Deutsches Herzzentrum München, Technische Universitat Munchen, Munich, Germany. ${ }^{5}$ Fraunhofer MEVI $\mathrm{S}$-Institute for Medical Image Computing, Bremen, Germany.

Received: 16 August 2020 Accepted: 14 October 2020

Published online: 06 November 2020

\section{References}

1. Kilner PJ, Gatehouse PD, Firmin DN (2007) Flow measurement by magnetic resonance: a unique asset worth optimising. J Cardiovasc Magn Reson 9: $723-728$ 
2. Petersen $\mathrm{SE}$, Voigtländer $\mathrm{T}$, Kreitner KF, Kalden $\mathrm{P}$, Wittlinger T, Scharhag J, Horstick G, Becker D, Hommel G, Thelen M, Meyer J (2002) Quantification of shunt volumes in congenital heart diseases using a breath-hold MR phase contrast technique-comparison with oximetry. Int J Cardiovasc Imaging 18: 53-60

3. Colletti PM (2005) Evaluation of intracardiac shunts with cardiac magnetic resonance. Curr Cardiol Rep 7:52-58

4. Brix L, Ringgaard S, Rasmusson A, Sørensen TS and Kim WY (2009). Threedimensional three component whole heart cardiovascular magnetic resonance velocity mapping: comparison of flow measurements from 3D and 2D acquisitions. J Cardiovasc Magn Reson 20:11:3.

5. François CJ, Srinivasan S, Schiebler ML, Reeder SB, Niespodzany E, Landgraf BR, Wieben O, Frydrychowicz A (2012). 4D cardiovascular magnetic resonance velocity mapping of alterations of right heart flow patterns and main pulmonary artery hemodynamics in tetralogy of Fallot. J Cardiovasc Magn Reson 7:14:16.

6. Geiger J, Markl M, Jung B, Grohmann J, Stiller B, Langer M, Arnold R (2011) 4D-MR flow analysis in patients after repair for tetralogy of Fallot. Eur Radiol 21:1651-1657

7. Geiger J, Markl M, Herzer L, Hirtler D, Loeffelbein F, Stiller B, Langer M, Arnold R (2012) Aortic flow patterns in patients with Marfan syndrome assessed by flow-sensitive four-dimensional MRI. J Magn Reson Imaging 35: 594-600

8. Sundareswaran KS, Haggerty CM, de Zélicourt D, Dasi LP, Pekkan K, Frakes DH, Powell AJ, Kanter KR, Fogel MA, Yoganathan AP (2012) Visualization of flow structures in Fontan patients using 3-dimensional phase contrast magnetic resonance imaging. J Thorac Cardiovasc Surg 143:1108-1116

9. Fratz S, Hess J, Schuhbaeck A, Buchner C, Hendrich E, Martinoff S, Stern H (2008). Routine clinical CMR in pediatric and adult congenital heart disease: patients, protocols questions asked and contributions. J Cardiovasc Magn Reson 17:10:46.

10. Knesewitsch T, Meierhofer C, Rieger H, Rößler J, Frank M, Martinoff S, Hess J, Stern H, Fratz S (2013). Demonstration of value of optimizing ECG triggering for cardiovascular magnetic resonance in patients with congenital heart disease. J Cardiovasc Magn Reson 16:15:3.

11. Meierhofer C, Schneider EP, Lyko C, Hutter A, Martinoff S, Markl M, Hager A, Hess J, Stern H, Fratz S (2013) Wall shear stress and flow patterns in the ascending aorta in patients with bicuspid aortic valves differ significantly from tricuspid aortic valves: a prospective study. Eur Heart J Cardiovasc Imaging 14:797-804

12. Nordmeyer S, Riesenkampff E, Messroghli D, Kropf S, Nordmeyer J, Berger F, Kuehne T (2013) Four-dimensional velocity-encoded magnetic resonance imaging improves blood flow quantification in patients with complex accelerated flow. J Magn Reson Imaging 37:208-216

13. Nordmeyer S, Riesenkampff E, Crelier G, Khasheei A, Schnackenburg B, Berger F, Kuehne T (2010) Flow-sensitive four-dimensional cine magnetic resonance imaging for offline blood flow quantification in multiple vessels: a validation study. Magn Reson Imaging 32:677-683

14. Dyverfeldt P, Bissell M, Barker AJ, Bolger AF, Carlhäll CJ, Ebbers T, Francios CJ, Frydrychowicz A, Geiger J, Giese D, Hope MD, Kilner PJ, Kozerke S, Myerson S, Neubauer S, Wieben O, Markl M (2015). 4D flow cardiovascular magnetic resonance consensus statement. J Cardiovasc Magn Reson 10; 17(1):72.

15. Kamphuis VP, Westenberg JJM, van der Palen RLF, Blom NA, de Roos A, van der Geest R, Elbaz MSM, Roest AAW (2017) Unravelling cardiovascular disease using four dimensional flow cardiovascular magnetic resonance. Int J Cardiovasc Imaging 33(7):1069-1081

16. Uribe S, Beerbaum P, Sørensen TS, Rasmusson A, Razavi R, Schaeffter T (2009) Four-dimensional (4D) flow of the whole heart and great vessels using real-time respiratory self-gating. Magn Reson Med 62:984-992

17. Ebel S, Dufke J, Köhler B, Preim B, Behrendt B, Riekena B, Jung B, Stehning C, Kropf S, Grothoff M, Gutberlet M (2020). Automated quantitative extraction and analysis of $4 \mathrm{D}$ flow patterns in the ascending aorta: an intraindividual comparison at 1.5 T and 3T. Sci Rep 10, 2949.

18. Lewandowski AJ, Raman B, Banerjee R, Milanesi M (2017) Novel insights into complex cardiovascular pathologies using 4D flow analysis by cardiovascular magnetic resonance imaging. Curr Pharm Des 23(22):32623267

19. Bonow RO (2008). Bicuspid aortic valves and dilated aortas: a critical review of the ACC/AHA practice guidelines recommendations, Am J Cardiol, vol. 102 (pg. 111-114).

\section{Publisher's Note}

Springer Nature remains neutral with regard to jurisdictional claims in published maps and institutional affiliations.

\section{Submit your manuscript to a SpringerOpen ${ }^{\circ}$ journal and benefit from:}

- Convenient online submission

- Rigorous peer review

- Open access: articles freely available online

- High visibility within the field

- Retaining the copyright to your article

Submit your next manuscript at $\boldsymbol{\nabla}$ springeropen.com 